\title{
GRAFENO COMO PROPOSTA MULTIDISCIPLINAR
}

\section{GRAPHENE AS A MULTIDISCIPLINARY PROPOSAL}

Davi Vieira Correia ${ }^{1}$; Lucas Oliveira do Rosário ${ }^{2}$; Mileny Ferreira Nascimento ${ }^{3}$; Alessandra Marcone Tavares Alves de Figueirêdo ${ }^{4}$

\section{INTRODUÇÃO}

O Grafeno é um nanomaterial que promete revolucionar a indústria tecnológica, devido as suas funções extraordinárias, além de substituir materiais com mais eficiência, como na condução elétrica e térmica. Por outro lado, esse material, geralmente, ainda não é retratado em cursos de graduação, devido à complexidade das suas propriedades físicas e químicas. Entretanto, é possível fazer discussões desse material a partir de assuntos iniciais nos cursos de Química, como ressonância e ligações químicas, como forma de contextualizar os conteúdos químicos.

Sob essa ótica, diversos assuntos, não retratados na ementa das disciplinas, podem e devem ser discutidos em formato de palestras, ou grupos, para uma melhor formação acadêmica do discente, promovendo a correlação com a sua vida social, além de prepará-lo para vislumbrar a Química no seu dia a dia. Sendo assim, o Grafeno mostra-se eficaz como conteúdo a ser abordado nas graduações de Química.

Destarte, o objetivo desse trabalho foi aplicar, no curso de Licenciatura em Química do Instituto Federal da Paraíba - IFPB, Campus João Pessoa, de maneira contextualizada ao cotidiano dos discentes, o nanomaterial "Grafeno", intuindo a contribuir para conhecimentos, fora da ementa disciplinar, por meio da palestra "Grafeno: a tecnologia do futuro".

\section{FUNDAMENTAÇÃO TEÓRICA}

\section{Grafeno}

O Grafeno é um nanomaterial que consiste em uma monoatômica de carbono, organizado em células hexagonais, com átomos de carbono hibridizados na forma $s p^{2}$, gerando elétrons livres por átomo de carbono no orbital $p$, tornando-o um material fantástico em várias aplicações, sendo assim, considerado melhor condutor elétrico que o silício, e melhor condutor

\footnotetext{
${ }^{1}$ Graduando em Licenciatura em Química, IFPB Campus João Pessoa, davivieiracorreia@ gmail.com

${ }^{2}$ Graduando em Licenciatura em Química, IFPB Campus João Pessoa, luca.s2016@ hotmail.com

${ }^{3}$ Graduanda em Licenciatura em Química, IFPB Campus João Pessoa, milenyferreira@live.com

${ }^{4}$ Doutora em Química, IFPB Campus João Pessoa, alessandratavaresfigueiredo@ifpb.edu.br
} 
térmico que o cobre (SEGUNDO; VILAR, 2015). Sintetizado pela primeira vez em 2004, o Grafeno foi isolado em pequenos pedaços, por meio do processo de "Esfoliação Mecânica", a partir do grafite, que logo com a caracterização, comprovaram que se tratava de uma única camada de carbono (FREIRE; GUIMARÃES, 2012).

Ademais, esse nanomaterial também é considerado 200 vezes mais forte que o aço, devido à sua característica peculiar, força essa ocasionada por estiramento das ligações Carbono-Carbono, pois "a ligação Csp2 - Csp2 é a mais forte existente na natureza, o que confere uma resistência extremamente elevada" (ZARBIN; OLIVEIRA, p. 1534, 2013).

Além disso, o Grafeno é alótropo do carbono, considerado o material "mãe" para a construção de nanoestruturas de carbono, com exceção do diamante (FREIRE; GUIMARÃES, 2012). Como pode ser visualizado, o Grafeno é um material tecnológico díspar, apresenta uma espetacular condutividade térmica e elétrica, assim como uma fantástica resistência.

\section{METODOLOGIA}

Para a presente pesquisa, utilizou-se a metodologia qualitativa e a participante. Esta última "caracteriza-se pelo envolvimento e identificação do pesquisador com as pessoas investigadas" (MATOS E LERCHE, 2001, p. 46). Por outro lado, na metodologia qualitativa, o pesquisador "é ao mesmo tempo o sujeito e o objeto de suas pesquisas" (DESLAURIERS, 1991, p. 58).

Previamente, houve uma pesquisa bibliográfica sobre a temática correspondente ao Grafeno, a fim de abordar esse tema atrelado a conceitos químicos. Portanto, o Grafeno foi escolhido como tema gerador e discorreu numa abordagem interativa e interdisciplinar, por intermédio da palestra intitulada "Grafeno: a tecnologia do futuro".

Tal palestra foi promovida por integrantes do Programa de Educação Tutorial - PET Química, numa atividade de ensino denominada “Ciclo de Palestras”, tendo como público alvo 14 graduandos em Licenciatura em Química do IFPB, Campus João Pessoa, tais discentes estavam locados entre o $2^{\circ}$ e o $4^{\circ}$ períodos do curso, na faixa etária de 19 (dezenove) a 29 (vinte e nove) anos. A princípio, no primeiro momento, foi entregue um Questionário de Sondagem (QS), em seguida, no segundo momento, ministrou-se a palestra e, após o término da apresentação desta, no terceiro momento, aplicou-se um Questionário Final (QF), ambos os questionários continham 4 (quatro) indagações abertas.

\section{RESULTADOS E DISCUSSÃO}

No primeiro momento da atividade de ensino, foi entregue o Questionário de Sondagem 
para o público participante, na intenção de verificar seu conhecimento prévio a respeito da temática a ser desenvolvida e, desse modo, favorecer a troca de saberes, durante a ministração do assunto, entre a plateia, composta por alunos do curso de Licenciatura em Química, e o palestrante.

Os dados evidenciados no QS foram analisados e se encontram descritos na sequência, identificados pela combinação entre a letra $Q$, maiúscula, seguida por um numeral correspondente a cada questionário respondido.

Referente a primeira questão: De acordo com seus pré-conhecimentos acerca de assuntos voltados à Química, do que se trata o grafeno? Apenas 14\% dos alunos souberam responder de forma correta a esta indagação, os demais obtiveram resultados equivocados e questões em branco. E apesar desse material estar sendo estudado a mais de 50 anos, por grupos de cientistas que almejavam sua obtenção na forma livre, como descrevem Zarbin e Oliveira (2013), as respostas a essa questão estão aquém do esperado. Por conseguinte, a segunda indagação, questionava-os sobre as características físicas e químicas do grafeno. Similarmente a questão anterior, somente $14 \%$ dispunha desta informação corretamente.

Abreviadamente, a terceira interpelação, perguntava de que modo esse material poderia ser utilizado em prol da sociedade atual. 29\% dos discentes souberam fornecer respostas satisfatórias, como pode ser observado nos Q8 e Q9, respectivamente: "Para otimizar a tecnologia em várias áreas da ciência”; "No desenvolvimento de nanotecnologias e pesquisas aeroespaciais".

Por possuir propriedades eletrônicas extraordinárias, o grafeno oferece para o mercado de nanomateriais ótimas propriedades térmicas e mecânicas, além de apresentar elevado potencial de condutividade. Por essa razão, sua aplicação pode ser destinada as mais diversas áreas, como a comunicação, optoeletrônica, compósitos, biomedicina e sensores, energia, aeronáutica e automotivos, entre outras (CAETANO, 2017).

Em alusão ao último questionamento: Na sua opinião, qual a importância do estudo de temas não abordados com frequência no curso de Licenciatura em Química? Nas respostas dos alunos, alguns pontos foram enfatizados com maior constância, como, a interdisciplinaridade e a importância de um repertório de conhecimentos vastos para a formação docente. Isto pode ser averiguado no Q3: “É importante para aumentar nosso conhecimento, e não ficar apenas em temas mais estudados" e no Q5: "É importante não só para a formação acadêmica, quanto para a prática docente".

Com relação à aquisição de conhecimento acerca de temas interdisciplinares, as Diretrizes Curriculares Nacionais (DCN) para a formação de professores da Educação Básica 
(Brasil, 2002), apontam a necessidade dos professores, em sua formação inicial, em desenvolver competências relacionadas ao domínio dos conteúdos a serem socializados, de seus significados em diferentes contextos e de sua articulação interdisciplinar. E ainda, esse mesmo documento atenta para a necessidade de que a interdisciplinaridade seja inserida na organização e desenvolvimento curricular do Ensino Superior para professores (BRASIL, 2002).

O segundo momento, foi proferida a exposição da palestra intitulada: "Grafeno: $a$ tecnologia do futuro" (Figura 1). Em que foram abordados tópicos referentes ao contexto histórico do grafeno, formas alotrópicas do carbono, áreas de aplicação, métodos de síntese do material, entre outros. No decorrer da apresentação, alguns questionamentos foram suscitados, assim, ocasionando momentos enriquecedores de debates, trocas de informações e construção de novos conhecimentos.

Figura 1: Palestra sobre Grafeno: a Tecnologia do futuro. Fonte: Própria

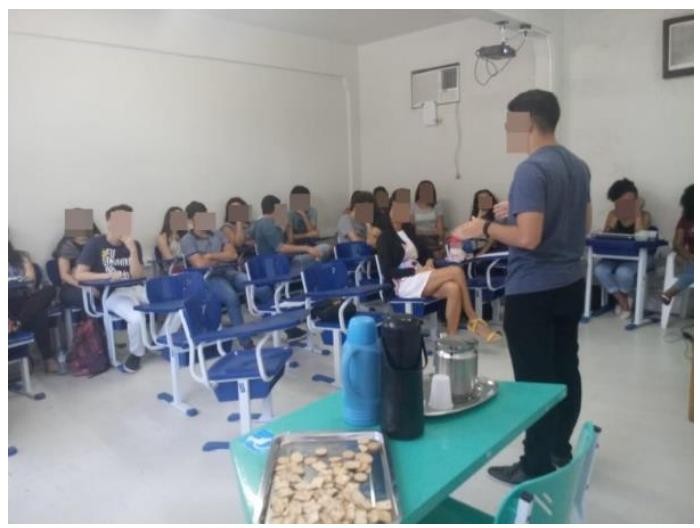

Nessa perspectiva, os Parâmetros Curriculares Nacionais para o Ensino Médio (PCNs) atestam para importância de estimular a interação entre aluno-aluno e aluno-mediador, pois momentos como estes favorecem o desenvolvimento de competências cognitivas superiores, além de, propiciar formas coletivas de conhecimento (BRASIL, 2000).

Algumas discussões ocasionadas durante a exposição da palestra aludiam acerca das excelentes propriedades de condução térmica e elétrica do grafeno, comparando-as com outros materiais, como o silício e o cobre, por exemplo. Tais questionamentos foram devidamente respondidos e esclarecidos. E por fim, prosseguiu-se para o terceiro e último momento da atividade, em que se realizou a entrega do QF, na intenção de avaliar a satisfação dos discentes com a palestra e a compreensão dos mesmos a respeito do assunto discutido.

A primeira indagação do QF, perguntava se a palestra havia contribuído com a formação acadêmica, na área de Química, do aluno. E todos os discentes respaldaram positivamente, como destacado nos Q3 e Q12, respectivamente: “Sim, pois com o conhecimento de tal 
material, poderemos futuramente, nos aprofundarmos no estudo de suas propriedades"; "Sim, pois é um assunto bem interessante, e contribuiu com meus conhecimentos, ampliando o olhar em novas áreas". Tais pronunciamentos enfatizam a relevância de abordar temáticas como essas, nos cursos de Licenciatura em Química.

No segundo e terceiro questionamento, pedia-se para que os alunos indicassem algumas áreas de aplicação do grafeno, assim como, descrevessem um dos métodos de síntese desse material, respectivamente. Em ambas as interrogações, os resultados assertivos foram unânimes, demostrando uma boa compreensão do assunto. Vale ressaltar que, um dos métodos de síntese mais ressalvados pelos estudantes, foi a esfoliação mecânica. Que, em suma, consiste em sucessivas etapas de peeling de um pedaço de grafite, com o auxílio de uma fita adesiva, método esse, que foi capaz de isolar e caracterizar o grafeno pela primeira vez em 2004, até então, tido como impossível (ZARBIN e OLIVEIRA, 2013).

A última questão, referia-se as dificuldades de obtenção do grafeno e sua consequente aplicação em áreas diversas. E, um dos principais problemas foram satisfatoriamente assinalados pelos respondentes, como se verifica no Q1: “O investimento financeiro é um grande empecilho para a obtenção e aplicação do grafeno”.

Por fim, é importante ressalvar o envolvimento dos estudantes com as discussões, originadas a partir da abordagem da temática relacionada a este material futurístico. Pois, tais discussões foram etapas fundamentais no desenvolvimento da palestra, proporcionando aos participantes, uma carga mais diversificada de conhecimentos que, como apontado nos questionários por alguns discentes, forneceram informações essenciais para a construção de novos conhecimentos.

\section{CONCLUSÕES}

O “Grafeno" tem características muito peculiares, tal material é candidato a movimentar várias áreas tecnológicas, bem como o setor industrial em diversas aplicações. Logo, é intrinsecamente indispensável inteirar os discentes de informações como estas que se relacionam com o cotidiano e tratam de temáticas além dos conteúdos inseridos na matriz curricular do curso de Licenciatura em Química.

Desta forma, com o emprego de uma metodologia diferenciada, como o ciclo de palestras proferido, é possível a introdução de materiais desse tipo, como modo de contextualização para conteúdos químicos. Contudo, a palestra permitiu a participação dos discentes, a troca de saberes e a contribuição na formação acadêmica na área de Química. 


\section{REFERÊNCIAS}

BRASIL. Parâmetro Curriculares Nacionais para o Ensino Médio. Secretaria de Educação Básica. - Brasília: Ministério da Educação, Secretaria de Educação Básica, 2000.

Diretrizes Curriculares Nacionais para a Formação de Professores da EducaçãoBásica, em nível superior, curso de licenciatura, de graduação plena. Resolução $\mathrm{CNE} / \mathrm{CPn}^{\circ} 1$, de 18 de fevereiro de $2002 \mathrm{a}$.

CAETANO, R. G. Grafeno: Características, propriedades e aplicações. 2017. 52f. Trabalho de Conclusão de Curso (Bacharel em Engenharia Química)-Centro Universitário de Formiga, Minas Gerais, 2017. Disponível em: <https://bibliotecadigital.uniformg.edu.br:21015/xmlui/handle/123456789/532>. Acesso em: 17/09/2018.

MATOS, K. S. L.; LERCHE, S. V. Pesquisa educacional: o prazer de conhecer. Fortaleza: Demócrito Rocha, 2001.

DESLAURIERS J. P. Recherche Qualitative. Montreal: McGraw Hill, 1991

FREIRE, A. D. J.; GUIMARÃES, M. J. O. C. Grafeno: Aplicações e Tendências Tecnológicas. Revista Química Industrial, Rio de Janeiro, n. 737, p. 14-19, set. 2012.

SEGUNDO, J. E. D.; VIEIRA, VILAR, E. O. Grafeno: Uma revisão sobre propriedades, mecanismos de produção e potenciais aplicações em sistemas energéticos. Revista Eletrônica de Materiais e Processos, v. 11, n. 2, p. 54 - 67, 2016.

ZARBIN, A. J. G. Nanoestruturas de carbono (nanotubos, grafeno): QUO VADIS?. Química Nova, v. 36, n. 10, p. 1533-1539, 2013. Disponível em: $<$ http://www.scielo.br/scielo.php?pid=S0100-

$40422013001000009 \&$ script=sci_abstract\&tlng=pt $>$. Acesso em: 17/09/2019. 